\title{
Effect of microwave irradiation on typical inorganic salts crystallization in membrane distillation process
}

\author{
Zhongguang $\mathrm{Ji}^{\mathrm{a}}$, Jun Wang ${ }^{\mathrm{a}, *}$, Zifei Yin ${ }^{\mathrm{b}}$, Deyin Hou ${ }^{\mathrm{a}}$, Zhaokun Luan ${ }^{\mathrm{a}}$ \\ a State Key Laboratory of Environmental Aquatic Chemistry, Research Center for Eco-Environmental Sciences, \\ Chinese Academy of Sciences, Beijing 100085, China \\ ${ }^{\mathrm{b}}$ School of Chemical E' Environmental Engineering, China University of Mining E' Technology (Beijing), Beijing 100083, China
}

\section{A R T I C L E I N F O}

\section{Article history:}

Received 28 June 2013

Received in revised form

9 December 2013

Accepted 24 December 2013

Available online 3 January 2014

Keywords:

Microwave irradiation

Membrane distillation

Sodium chloride

Calcium carbonate

Crystallization

\begin{abstract}
A B S T R A C T
This study is a continuation of our previous work on microwave-assisted membrane distillation. The crystal morphology of sodium chloride and calcium carbonate in the process of membrane distillation and microwave membrane distillation was investigated in this work. The effect of salt concentration on the ability of absorbing microwave of solution and the mass transfer of microwave membrane distillation were also analyzed. The results show that the ionic conduction is the main between two factors (ionic conduction and dipole rotation) which have effect on absorbing microwave. When the mass concentration of sodium chloride solution is up to $5 \%$, the microwave energy absorbed by solution is almost five times as much as pure water. Moreover, the increase in salt concentration has no significant extra influence on the mass transfer of microwave membrane distillation. The crystallization experiments confirm that microwave irradiation do not affect membrane fouling or worsen it. The different effect of microwave irradiation on crystallization of two typical inorganic salts is observed in this study. For sodium chloride, the microwave heating leads to the decline of the total particle number, while the total deposition keeps constant and the size distribution of crystal particles becomes more uniform, compared with conventional heating. As for calcium carbonate, microwave irradiation not only increases the total deposition and total particle number, but also induces the crystals growth. Especially, it is found that microwave irradiation induces the crystals to grow toward aragonite. The ratios of the aragonite number to the total particle number increase from $28.0 \%$ and $56.5 \%$ to $81.1 \%$ and $85.8 \%$ at the two higher feed mass concentrations, respectively.
\end{abstract}

(c) 2014 Elsevier B.V. All rights reserved.

\section{Introduction}

Membrane distillation is considered to be a promising technology for desalination of high concentration salty water. However, there are still some obstacles, such as inadequate permeate flux for amplified reactor and membrane fouling, which impede the largescale application of membrane distillation [1,2]. For solving these problems, many efforts have been done on setting turbulentinducing components in flow channel of membrane module [35] and coupling ultrasonic technique with membrane distillation [6]. Specially, our research team introduced microwave technique into membrane distillation process for investigating the effect of microwave irradiation on the mass transfer of vacuum membrane distillation (VMD) [7]. It was found that the mass transfer was improved significantly under microwave irradiation. But the effect of microwave irradiation on crystallization was still confusing.

It is generally believed that microwave irradiation produces two effects: thermal effect and non-thermal effect (special effect)

\footnotetext{
* Corresponding author. Tel.: +86 10 62849198; fax: +86 1062859198 .

E-mail address: junwang@rcees.ac.cn (J. Wang).
}

[8]. The special effect is an interesting and often confusing phenomenon in many researches, such as microwave-assisted synthesis or preparation of organic compounds [9-14], microwave-enhanced molecules diffusion in polymeric materials $[15,16]$ and microwave-assisted extraction or removal [17-21]. It is considered by many scholars that the light quantum (the quantum of electromagnetic radiation) of microwave has some special effects on reducing the Gibbs free energy of activation of reactions. The effects may be shown in two respects: (1) microwave energy is absorbed and stored in the internal molecule; (2) the arrangement of molecules is changed [8]. Moreover, in a liquid reaction system, the polar molecules irradiated by microwave change directions quickly to form a "micro-agitation" effect, which can also be considered as a microwave special effect.

For ionic solutions placed in a microwave field, the ions will migrate toward corresponding electric field direction and change migration direction continuously with the alternation of the electric field. Based on this principle, it has been confirmed that the rate of ion exchange can be enhanced by using microwave as heat source for ion exchange reactions [22]. This mode of ion migration and changing direction has a special effect on crystallization process. 
Microwave irradiation has been applied directly in salt crystallization from ionic solutions. Rodriguez-Clemente and GomezMorales [23] found in precipitation of $\mathrm{CaCO}_{3}$ from homogeneous solutions that a higher rate of nucleation and greater particle size uniformity can be obtained under microwave heating. Yang et al. [24] did research on $\mathrm{CaSO}_{4}$ crystallization process, the results of which showed that there was significant difference on the crystal morphology between two operation conditions of microwave heating and conventional heating.

Inorganic salt crystallization is a conventional phenomenon in desalination by membrane distillation. It was found occasionally in our research on desalination by microwave vacuum membrane distillation that microwave irradiation might aggravate membrane fouling [7]. So, in this work, the effect of microwave irradiation on inorganic salt crystallization in membrane distillation is studied systematically. This work mainly focuses on the behavior of two typical inorganic salts in the process of microwave membrane distillation (MWMD).

\section{Experimental}

\subsection{Materials and membrane module}

One PVDF flat membrane (FluoroTrans ${ }^{\circledR}$ ) with a nominal pore size of $0.2 \mu \mathrm{m}$ and a thickness of $127 \mu \mathrm{m}$, which was purchased from Pall Co., was chosen to fabricate membrane modules. The flat membrane was clipped by two PTFE plates with parallel grooves. And these components were fixed using PTFE screws through the edges of the two plates. The reason for using the PTFE plates and screws is that the microwave dielectric loss of the PTFE materials is very small. Therefore, the membrane module can be placed in microwave cavity for a long time. The effective membrane area of the module is about $0.0029 \mathrm{~m}^{2}$. The characteristics of the membrane material and the module are presented in Table 1.

\section{2. $M W M D$ setup}

The MWMD experimental setup is schematically shown in Fig. 1. The salt solution, which was stirred continually by a magnetic stirrer, was heated to one certain temperature by a constant temperature water bath, and then circulated through the hot side of the module using a cycle water pump. The steam flowed through membrane pores into the cold side of the module and was captured by coolant, the pure water. Then the condensate was carried into coolant bottle. The overflow entered into measuring cylinder and was measured by electronic balance. In the process of circulation, the membrane module was radiated continually by microwave $(2.45 \mathrm{GHz}, 700 \mathrm{~W})$, which was provided by household microwave oven. The temperature and velocity of the solution in the module inlet and outlet were monitored by temperature meter and rotameter, respectively. The conductivity meter was used to monitor the conductivity of the liquid in the coolant bottle.

Table 1

The characteristics of the membrane material and the module.

\begin{tabular}{ll}
\hline Membrane and module & Properties \\
\hline Membrane material & PVDF \\
Nominal pore size $(\mu \mathrm{m})$ & 0.2 \\
Thickness $(\mu \mathrm{m})$ & 127 \\
Porosity $(\%)$ & 75 \\
Effective membrane area $\left(\mathrm{m}^{2}\right)$ & 0.0029 \\
\hline
\end{tabular}

Sodium chloride and calcium carbonate as the typical inorganic salts in water were chosen as research objects. And a series of experiments with MD and MWMD were conducted to investigate the effect of microwave irradiation on crystallization process of sodium chloride and calcium carbonate.

\subsection{Crystal morphology analysis}

For investigating the morphology of the crystals deposited on the membrane surface, scanning electron microscopy (SEM) and two image analysis software were adopted. The precise information of the crystal morphology could be acquired through certain treatment to the SEM images by software.

First, the images of the crystals on membrane surface were obtained by a scanning electron microscopy (HITACHI, S-3000N).

Then, two image analysis softwares including Nano Mesurer (1.2) and Imagej (1.44i) were adopted to analyze the crystal morphology. For the image which has a relatively obvious boundary in color between crystals and the background of the membrane surface, Imagej (1.44i) can automatically recognize and extract the crystal objects through adjusting the gray scale of the image. After special treatment, this software can provide much information about the crystal particles in the image, such as particle size and count, total area and area fraction, etc. If the image has not a relatively significant boundary in color between crystals and background, the other software named Nano Mesurer (1.2) will be introduced to the treatment of the image. But the precondition is that the crystals can be identified by the naked eyes. Each recognizable crystal is numbered manually, then the crystal size is measured by software.

\section{Results and discussions}

\subsection{Effect of sodium chloride concentration on the MWMD process}

Two phenomena, dipole rotation and ionic conduction, will occur in inorganic salt solution, if the solution is exposed to microwave irradiation. Therefore, the ion concentration may have a great impact on absorbing microwave of the solution and the mass transfer of the MWMD process. For clarifying this point, sodium chloride solution was chosen to implement a series of experiments at eight concentration levels with conditions of feed velocity of $1.1 \mathrm{~m} / \mathrm{s}$ and feed average temperature of $54{ }^{\circ} \mathrm{C}$. In addition, the inlet temperature and the velocity of the coolant (pure water) were set to $10{ }^{\circ} \mathrm{C}$ and $0.5 \mathrm{~m} / \mathrm{s}$, respectively.

First, the effect of sodium chloride concentration on the ability of absorbing microwave of the solution was investigated. On the condition that the average temperature was set to a constant value of $54{ }^{\circ} \mathrm{C}$ and no coolant fluid was added in the cold side of the module, the inlet temperatures of the solution under conventional heating and microwave heating were both measured. Normally, when the feed solution flows through the module, natural heat loss will appear. Microwave irradiation can effectively compensate the heat loss. The temperature increment caused by absorbing microwave can be obtained from Eq. (1)

$\Delta T=\left(T_{\text {wo }}-T_{\text {wi }}\right)-\left(T_{\text {co }}-T_{\text {ci }}\right)$

where $\Delta T$ is the temperature increment caused by absorbing microwave. $T_{\text {wo }}$ and $T_{\text {wi }}$ are the outlet and inlet temperatures of the feed solution in module channel under microwave heating, respectively. For the same reason, $T_{\mathrm{co}}$ and $T_{\mathrm{ci}}$ are the outlet and inlet temperatures of the feed solution under conventional heating, respectively.

The effect of sodium chloride concentration on absorbing microwave of the solution is presented in Fig. 2. It can be seen 


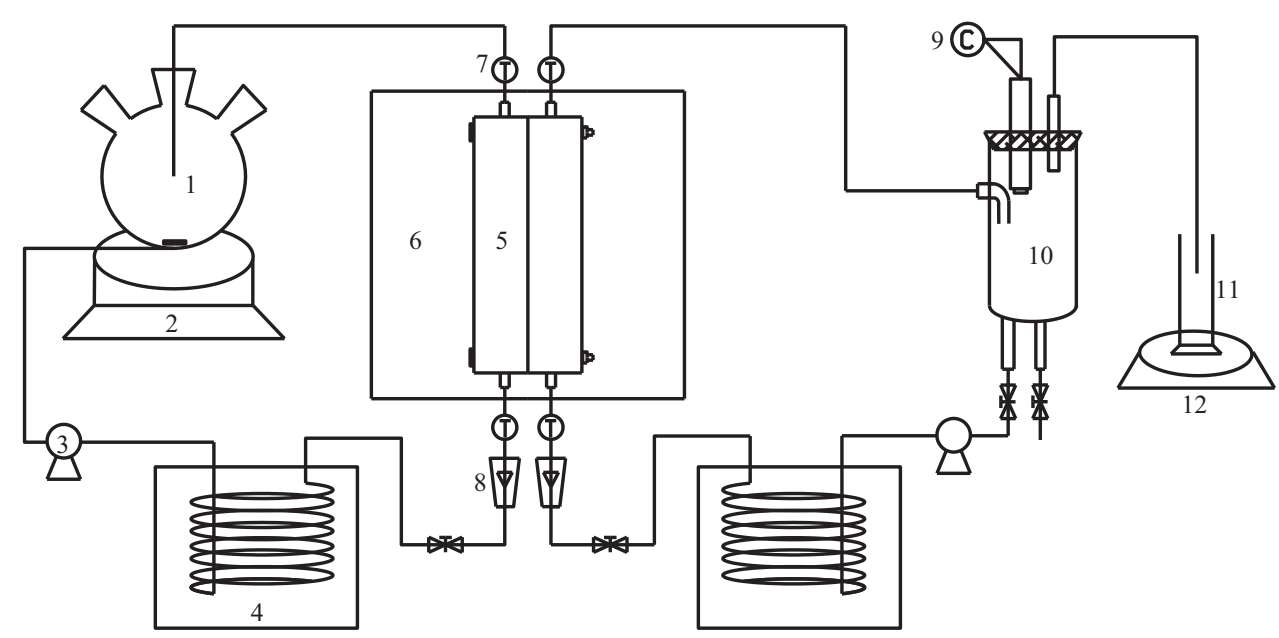

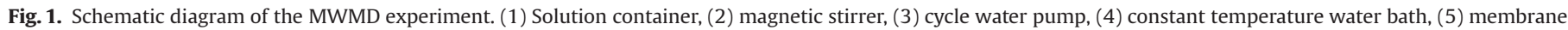
module, (6) microwave oven, (7) temperature meter, (8) rotameter, (9) conductivity meter, (10) coolant bottle, (11) measuring cylinder, and (12) electronic balance.

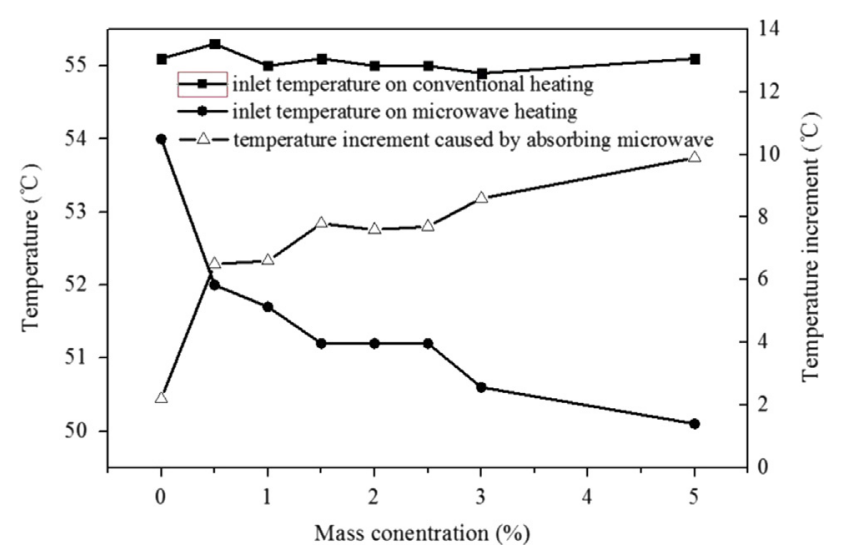

Fig. 2. The effect of sodium chloride concentration on solution absorbing microwave energy.

from Fig. 2 that on condition of the same average temperature of $54{ }^{\circ} \mathrm{C}$, inlet temperatures needed on microwave heating are evidently lower than that on conventional heating. The increase of the solution concentration has less influence on the inlet temperature under conventional heating, but cause the decrease of the inlet temperature under microwave heating obviously. When the mass concentration is up to $5 \%$, the inlet temperature under microwave irradiation decreases to $50.1^{\circ} \mathrm{C}$, while the value under conventional heating is $55.1^{\circ} \mathrm{C}$.

The most visual parameter for reflecting the influence of solution concentration on absorbing microwave is temperature increment caused by absorbing microwave $(\Delta T)$, which is proportional to the microwave energy absorbed by the solution. It can be seen from Fig. 2 that the ddition of sodium chloride has a significant effect on absorbing microwave of the solution. When the mass concentration increases from $0 \%$ to $0.5 \%, \Delta T$ increases from $2.2{ }^{\circ} \mathrm{C}$ to $6.5^{\circ} \mathrm{C}$. And when the mass concentration is up to $5 \%$, the $\Delta T$ is $9.9^{\circ} \mathrm{C}$, which is nearly five times than the original value of $2.2{ }^{\circ} \mathrm{C}$. It is also very obvious from Fig. 2 that the higher the mass concentration, the greater the $\Delta T$.

The results above indicate that the ionic conduction in salt solution indeed plays an important role in microwave heating. Especially on the condition in this research, the ionic conduction is the main one between two factors (ionic conduction and dipole rotation) which have effect on absorbing microwave of ionic solution. It also can be concluded that the conventional energy provided for the preheating of ionic solution can be saved much

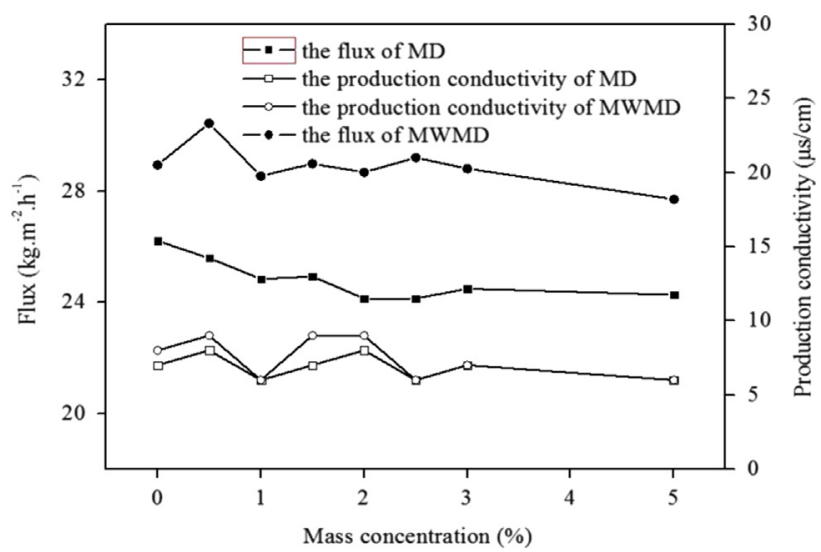

Fig. 3. The effect of sodium chloride concentration on the flux and water production quality of MWMD.

under microwave irradiation. For instance, under both operation methods in this research, the constant temperature water bath was respectively set to $62{ }^{\circ} \mathrm{C}$ and $48{ }^{\circ} \mathrm{C}$ with conditions of the average feed temperature of $54{ }^{\circ} \mathrm{C}$, the feed velocity of $1.1 \mathrm{~m} / \mathrm{s}$ and the mass concentration of $3 \%$. Moreover, the conventional energy demanded decreases with the mass concentration increase of ionic solution under microwave irradiation. However, it should also be considered that the conversion efficiency of electric energy to microwave energy and the utilization efficiency of microwave energy are both limited. Therefore, in order to achieve the goal of energy savings in the process of microwave application in membrane distillation, equipment improvement and process optimization are necessary. Second, the effect of sodium chloride concentration on the mass transfer of MWMD process was also investigated. In addition to maintaining the operation conditions in feed side above, the coolant (pure water) was filled and circulated in the cold side. And the temperature and velocity of the coolant were set to $10{ }^{\circ} \mathrm{C}$ and $0.5 \mathrm{~m} / \mathrm{s}$, respectively. The permeate flux and conductivity were measured. The results are presented in Fig. 3.

It can be seen from Fig. 3 that the MWMD flux is obviously higher than the MD flux at the same feed average temperature. The fluxes of two processes both decrease slightly with the increase of mass concentration, which is related to the concentration polarization, a common phenomenon in membrane distillation. It is definite that microwave irradiation can strengthen the 
mass transfer of membrane distillation. It is also showed in Fig. 3 that microwave irradiation has no evident influence on production quality. That is said, microwave irradiation can accelerate the vapor molecule except $\mathrm{Na}^{+}$and $\mathrm{Cl}^{-}$through membrane pores.

The results of this study indicate that properly increasing the mass concentration of ionic solution can not only save conventional energy greatly, but also be beneficial to maintain higher flux in lower inlet temperature of feed solution under microwave irradiation.

\subsection{Effect of microwave irradiation on the crystal morphology of sodium chloride}

Sodium chloride is a common inorganic salt in water treatment. The sodium chloride crystallization is also a universal phenomenon in membrane distillation. Therefore, when microwave technology is coupled with membrane distillation process, the effect of microwave irradiation on crystallization of sodium chloride should be investigated.

Sodium chloride is white crystal, and has only one crystal phase. So the mass concentration has no impact on the crystal phase of sodium chloride. The solution containing sodium chloride of $0.5 \mathrm{wt} \%$ is chosen as the feed to conduct MD and MWMD processes for $40 \mathrm{~min}$, respectively. Other conditions are the same as those above. The form of the crystals can be observed from Fig. 4. The images in Fig. 4 are obtained through adjusting the gray scale of the original SEM images by Imagej, and are suited to analyze. The analysis results of the crystal particles in Fig. 4 are listed in Table 2.

The definition of all parameters in Table 2 is explained first. Particle number is the quantity of all particles on the surface of membrane. Total area is the sum of the areas of all particles. Average size is the ratio of the total area to the particle number. Area fraction is the ratio of the total area to the image area. Standard deviation represents the uniformity of the particle size. In addition, the unit symbol of both the total area and the average size is pixel $^{2}$ (image pixel, $640 \times 480$ ).

It can be seen from Table 2 that the particle number under microwave irradiation is less than that under conventional heating. However, the values of the total area and the area fraction also show that microwave irradiation does not make the total deposition of sodium chloride increase obviously, compared with conventional heating. The area fractions under both heating modes are $4.4 \%$.

Although microwave irradiation has no significant effect on crystallization amount of sodium chloride in membrane distillation, the difference of standard deviation under both heating modes shows that microwave irradiation affects the uniformity of the crystal particles. The standard deviation under microwave heating is 61.10, which is less than 91.07 under conventional heating. This result can also be seen visually from Fig. 4 .

It can be concluded that microwave irradiation decreases the number of the crystal particles of sodium chloride, while the total deposition keeps constant. The other conclusion is that microwave irradiation can make the size distribution of crystal particles more uniform.

\subsection{Effect of microwave irradiation on the crystal morphology of calcium carbonate}

Calcium carbonate is common in water and widely studied as a typical mineral. Calcium carbonate crystals have three phases: calcite, aragonite and vaterite. Calcite is most thermodynamically stable among three phases, while vaterite is most unstable. Vaterite is the original phase in the process of calcium carbonate precipitation, then transforms into aragonite or calcite $[25,26]$.

In this work, calcium carbonate was chosen as another research object to investigate the influence of microwave irradiation on the crystallization in membrane distillation. The $\mathrm{CaCl}_{2}$ solution and the $\mathrm{Na}_{2} \mathrm{CO}_{3}$ solution with corresponding concentration were mixed to prepare supersaturated solution. The supersaturation $(S)$ of the solution can be calculated by Eq. (2).

$S=\frac{\left[\mathrm{Ca}^{2+}\right]\left[\mathrm{CO}_{3}{ }^{2-}\right]}{K_{\mathrm{sp}}\left(\mathrm{CaCO}_{3}\right)}$

Table 2

The statistical analysis result of sodium chloridecrystal particles.

\begin{tabular}{lcc}
\hline & MD & MWMD \\
\hline Particle number & 482 & 428 \\
Total area $\left(\right.$ pixel $\left.^{2}\right)$ & 13,640 & 13,722 \\
Average size $\left(\right.$ pixel $\left.^{2}\right)$ & 28.30 & 32.06 \\
Area Fraction (\%) & 4.4 & 4.4 \\
Standard deviation & 91.07 & 61.10 \\
\hline
\end{tabular}

Table 3

The concentration of all initial solutions and the supersaturation.

\begin{tabular}{llc}
\hline$\left[\mathrm{Ca}^{2+}\right](\mathrm{mmol} / \mathrm{L})$ & {$\left[\mathrm{CO}_{3}{ }^{2-}\right](\mathrm{mmol} / \mathrm{L})$} & Supersaturation \\
\hline 0.75 & 0.75 & 115 \\
1.5 & 1.5 & 460 \\
3 & 3 & 1840 \\
3.75 & 3.75 & 2875 \\
\hline
\end{tabular}

b

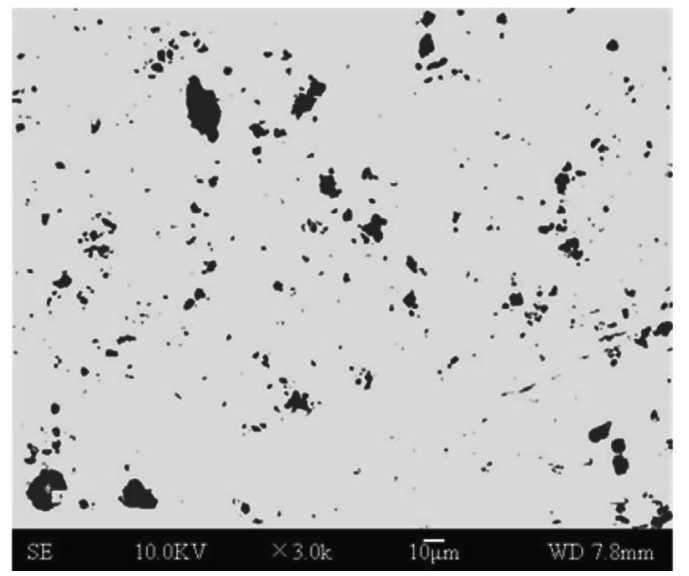

Fig. 4. The SEM morphology of the crystal on membrane surface. (a) MD. (b) MWMD. 
where $\left[\mathrm{Ca}^{2+}\right]$ and $\left[\mathrm{CO}_{3}{ }^{2-}\right]$ are the concentrations of $\mathrm{Ca}^{2+}$ and $\mathrm{CO}_{3}{ }^{2-}$, respectively. $K_{\mathrm{sp}}\left(\mathrm{CaCO}_{3}\right)$ is the solubility product of calcium carbonate, $4.9 \times 10^{-9}$ at $298.15 \mathrm{~K}$. The $\mathrm{CaCl}_{2}$ solution was set to four different concentrations. The concentration of all initial solutions and the corresponding supersaturation are given in Table 3. The average temperatures of the feed solution and the condensate were set to $70^{\circ} \mathrm{C}$ and $20^{\circ} \mathrm{C}$, respectively. And the flow rates of the feed solution and the condensate were set to $0.05 \mathrm{~m} / \mathrm{s}$
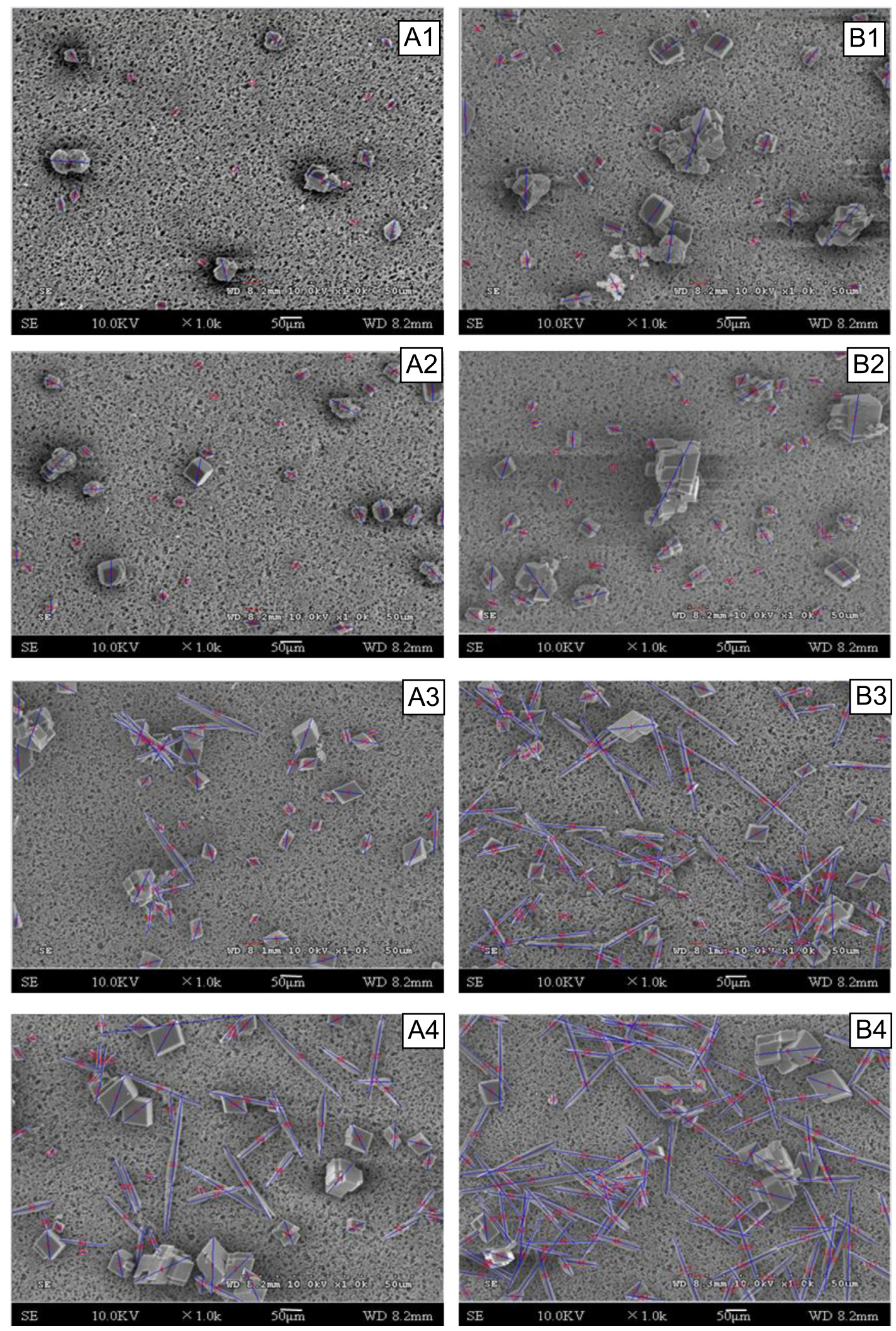

Fig. 5. The SEM morphology of the crystal on membrane surface: (A1) supersaturation 115 in MD, (A2) supersaturation 460 in MD, (A3) supersaturation 1840 in MD, (A4) supersaturation 2875 in MD; (B1) supersaturation 115 in MWMD, (B2) supersaturation 460 in MWMD, (B3) supersaturation 1840 in MWMD, (B4) supersaturation 2875 in MWMD. 
and $0.5 \mathrm{~m} / \mathrm{s}$, respectively. Under the conditions above, a series of supersaturated solutions were prepared as feed solution to conduct MD and MWMD processes for $90 \mathrm{~min}$. The crystal morphology on membrane surface was observed by SEM. The results are presented in Fig. 5.

Considering that the color threshold between the crystal of calcium carbonate and the membrane surface is not well-defined, another image processing software Nano Measurer (1.2.5) was adopted to assist in analyzing the crystal morphology on the membrane surface. The easy analysis process is as follow: (1) setting a scale, (2) marking each crystal particle, (3) statistic analysis by software program. The images with marked crystals are also displayed in Fig. 5. And the results of the statistic analysis can be seen from Figs. 6-8 and Table 4.

In Fig. $6, \Delta N$ of the right $Y$ axis is the difference between the total particle numbers of the MWMD and the MD process. It can be seen from Fig. 6 that the number of the total particles on the membrane surface in the MWMD process is obviously larger than the MD process at each feed concentration. Furthermore, with the increase of the supersaturation, $\Delta N$ significantly becomes larger. Fig. 7 indicates that the mean size of all particles in the MWMD process is larger than the MD process at each feed concentration. Therefore, for $\mathrm{CaCO}_{3}$ crystallization, microwave irradiation not only aggravates the sedimentation, but also strengthens the crystal growth.

Rodriguez and Gomez [23] found in their study on crystal deposition from a homogeneous solution containing $\mathrm{Ca}^{2+}$ and

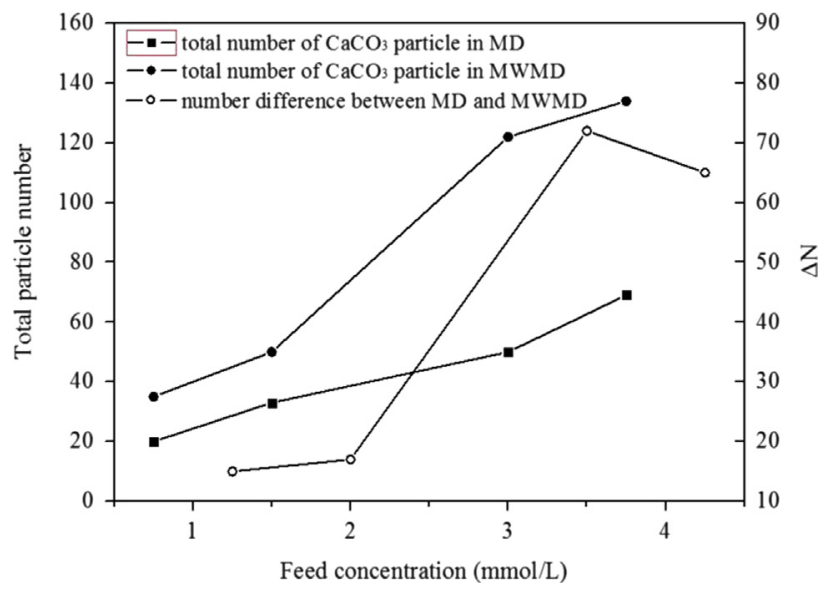

Fig. 6. The influence of microwave irradiation on total crystal particle number.

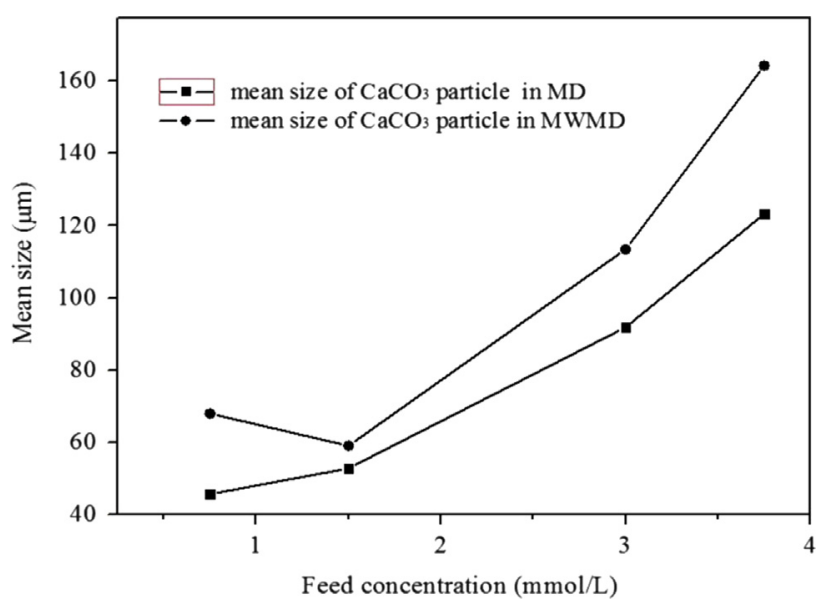

Fig. 7. The influence of microwave irradiation on mean size of crystal particle.

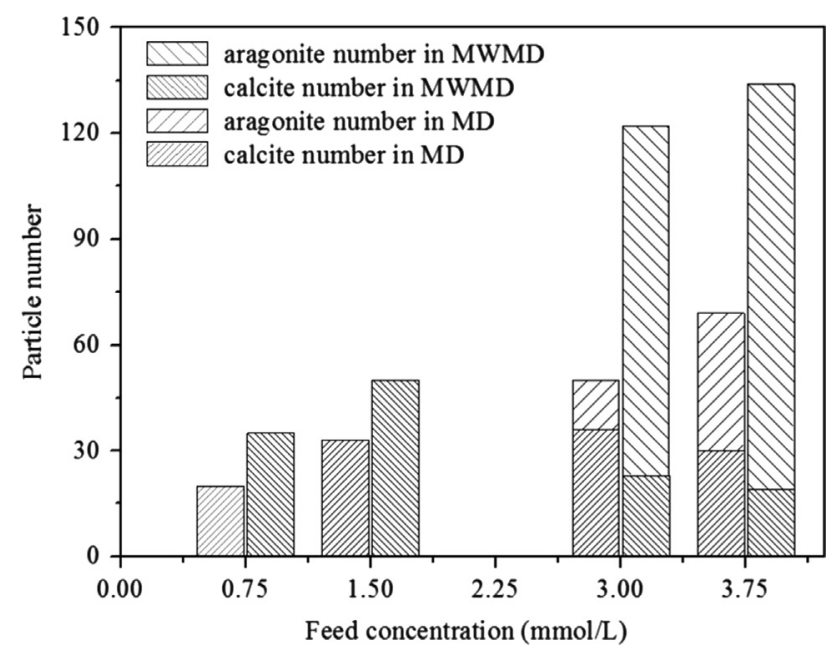

Fig. 8. The influence of microwave irradiation on crystal phase.

Table 4

The quantity of two crystal phases of calcium carbonate in MD and MWMD process.

\begin{tabular}{|c|c|c|c|c|c|c|}
\hline \multirow[t]{2}{*}{ Supersaturation } & \multicolumn{3}{|c|}{ Particle number in MD } & \multicolumn{3}{|c|}{ Particle number in MWMD } \\
\hline & Calcite & Aragonite & $\begin{array}{l}\text { Ratio of } \\
\text { aragonite } \\
(\%)\end{array}$ & Calcite & Aragonite & $\begin{array}{l}\text { Ratio of } \\
\text { aragonite } \\
(\%)\end{array}$ \\
\hline 115 & 20 & 0 & 0 & 35 & 0 & 0 \\
\hline 460 & 33 & 0 & 0 & 50 & 0 & 0 \\
\hline 1840 & 36 & 14 & 28.0 & 23 & 99 & 81.1 \\
\hline 2875 & 30 & 39 & 56.5 & 19 & 115 & 85.8 \\
\hline
\end{tabular}

$\mathrm{HCO}_{3}{ }^{-} / \mathrm{CO}_{3}{ }^{2-}$ that microwave heating caused a faster nucleation speed and a more uniform size distribution, compared with conventional heating. It is considered that molecule agitation in solution introduced by microwave irradiation breaks the hydrated cation clusters and the diffusion ability of ions is strengthened, which increases the probability of collision crystallization between ions in solution and crystals in deposit. The theory is also suitable for membrane distillation process. Furthermore, because of the positive correlation between solution concentration and the ability of absorbing microwave, the difference of the particle numbers between two processes increases with the solution concentration, which can be seen from Fig. 6 .

If taking the crystallization experiment of sodium chloride into consideration, it can be seen that microwave irradiation has different effects on the crystallization of sodium chloride and calcium carbonate. Comparing microwave heating with conventional heating, it shows that the total deposition of sodium chloride remains almost unchanged, while the total deposition of calcium carbonate increases obviously. It is supposed that ionization and molecule agitation are the two influence factors of the crystallization process under microwave irradiation. Ionization accelerates the crystallization, while molecule agitation restrains. It is also well known that the solubility product of calcium carbonate is much less than sodium chloride. Consequently, the intensification of ionization degree provides more chance of collision crystallization for calcium carbonate, while the ionization effect is obviously counteracted by molecule agitation for sodium chloride. Therefore, microwave irradiation has different effects on the crystallization of calcium carbonate and sodium chloride.

It is mentioned that the calcium carbonate has three crystal phases: calcite, aragonite and vaterite. It can be seen from Fig. 5 that there are two main shapes of crystals: hexagonal crystals and whiskers. The hexagonal crystals are calcite, and the whiskers are 
aragonite [27]. Fig. 8 shows that microwave irradiation has effect on phase distribution. At the lower supersaturations of 115 and 460 , all crystals are calcite in the two processes, while at the higher supersaturations of 1840 and 2875, more crystals selectively grow toward aragonite in the MWMD process, compared with the MD process. It can be seen clearly in Table 4 that the ratios of the aragonite number to the total particle number increase from $28.0 \%$ and $56.5 \%$ to $81.1 \%$ and $85.8 \%$ at the two higher supersaturations, respectively. Actually, within a fixed operation time and a region of the membrane surface, there is a positive correlation between the ratio of the aragonite and the total deposition. It also has been known from Fig. 6 that microwave irradiation can increase the total deposition. Therefore, it should be further investigated that if microwave irradiation has extra special effect on the formation of aragonite.

\section{Conclusions}

The crystal morphology of sodium chloride and calcium carbonate under two heating modes in membrane distillation process was investigated. The effect of salt concentration on the absorbing microwave energy of solution and the mass transfer of MWMD process were also analyzed. Several conclusions are listed below:

(1) It is confirmed from the crystallization experiments that microwave irradiation do not affect membrane fouling or worsen it.

(2) The ionic conduction is the main one between two factors (ionic conduction and dipole rotation) which have effect on the absorbing microwave energy of solution. The increase of mass concentration has no significant extra influence on the strengthening effect of microwave irradiation and the production quality in the MWMD process.

(3) Microwave irradiation has different effect on the crystallization of sodium chloride and calcium carbonate. For sodium chloride, microwave irradiation decreases the number of the crystals deposited on the membrane surface, while the total deposition keeps constant and the size distribution of the crystals becomes more uniform. As for calcium carbonate, microwave irradiation not only increases the total deposition and total particle number, but also induces the crystal growth. Moreover, microwave irradiation increases the ratios of aragonite number to the total particle number. However, if this transformation of crystal phase is entirely attributed to microwave irradiation should be investigated intensively.

In addition, based on the results above, microwave irradiation may be an attractive application for special aim in adjusting crystal phase in the process of inorganic salt crystallization.

\section{Acknowledgment}

Financial support from Key Program of the National Natural Science Foundation of China No. 51378491 and 51138008).

\section{References}

[1] M. Gryta, Fouling in direct contact membrane distillation process, J. Membr. Sci. 325 (2008) 383-394.

[2] D.R.L. Kevin, W. Lawson, Membrane distillation, J. Membr. Sci. 124 (1997) 25

[3] V.D.A. Tzahi, Y. Cath, Amy E. Childress, Experimental study of desalination using direct contact membrane distillation: a new approach to flux enhancement, J. Membr. Sci. 228 (2004) 5-16.

[4] J. Phattaranawik, R. Jiraratananon, A.G. Fane, C. Halim, Mass flux enhancement using spacer filled channels in direct contact membrane distillation, J. Membr. Sci. 187 (2001) 193-201.

[5] S.B. May May Teoh, Tai-Shung Chung, Investigation of different hollow fiber module designs for flux enhancement in the membrane distillation process, J. Membr. Sci. 311 (2008) 371-379.

[6] C. Zhu, G.L. Liu, Modeling of ultrasonic enhancement on membrane distillation, J. Membr. Sci. 176 (2000) 31-41.

[7] Z.G. Ji, J. Wang, D.Y. Hou, Z.F. Yin, Z.K. Luan, Effect of microwave irradiation on vacuum membrane distillation, J. Membr. Sci. 429 (2013) 473-479.

[8] S.A. Galema, Microwave chemistry, Chem. Soc. Rev. 26 (1997) 6.

[9] A. de la Hoz, A. Diaz-Ortiz, A. Moreno, Microwaves in organic synthesis Thermal and non-thermal microwave effects, Chem. Soc. Rev. 34 (2005) 164-178.

[10] R.N. Gedye, W. Rank, K.C. Westaway, The rapid synthesis of organiccompounds in microwave-ovens.2, Can. J. Chem.-Rev. Can. Chim. 69 (1991) 706-711.

[11] F. Langa, P. DelaCruz, A. DelaHoz, A. DiazOrtiz, E. DiezBarra, Microwave irradiation: more than just a method for accelerating reactions, Contemp. Org. Synth. 4 (1997) 373-386.

[12] Y. Mansourpanah, S.S. Madaeni, A. Rahimpour, Preparation and investigation of separation properties of polyethersulfone supported poly(piperazineamide) nanofiltration membrane using microwave-assisted polymerization, Sep. Purif. Technol. 69 (2009) 234-242.

[13] A. Huang, W. Yang, Hydrothermal synthesis of NaA zeolite membrane together with microwave heating and conventional heating, Mater. Lett. 61 (2007) 5129-5132.

[14] H. Zhou, Y. Li, G. Zhu, J. Liu, W. Yang, Preparation of zeolite T membranes by microwave-assisted in situ nucleation and secondary growth, Mater. Lett. 63 (2009) 255-257.

[15] C. Gibson, I. Matthews, A. Samuel, Microwave enhanced diffusion in polymeric materials, J. Microw. Power EE 23 (1988) 17-28.

[16] Y. Nakai, H. Yoshimizu, Y. Tsujita, Enhanced gas permeability of cellulose acetate membranes under microwave irradiation, J. Membr. Sci. 256 (2005) $72-77$.

[17] Y.X. Hua, C.J. Cai, Y. Cui, Microwave-enhanced roasting of copper sulfide concentrate in the presence of $\mathrm{CaCO}_{3}$, Sep. Purif. Technol. 50 (2006) 22-29.

[18] J.G. Gujar, S.J. Wagh, V.G. Gaikar, Experimental and modeling studies on microwave-assisted extraction of thymol from seeds of Trachyspermum ammi (TA), Sep. Purif. Technol. 70 (2010) 257-264.

[19] X. Li, X. Zhang, L. Lei, Preparation of CuNaY zeolites with microwave irradiation and their application for removing thiophene from model fuel, Sep. Purif. Technol. 64 (2009) 326-331.

[20] L. Lei, X. Li, X. Zhang, Ammonium removal from aqueous solutions using microwave-treated natural Chinese zeolite, Sep. Purif. Technol. 58 (2008) 359-366.

[21] L. Lin, S. Yuan, J. Chen, Z. Xu, X. Lu, Removal of ammonia nitrogen in wastewater by microwave radiation, J. Hazard. Mater. 161 (2009) 1063-1068.

[22] D.E. Clark, D.C. Folz, J.K. West, Processing materials with microwave energy, Mat. Sci. Eng. A-Struct. 287 (2000) 153-158.

[23] R. RodriguezClemente, J. GomezMorales, Microwave precipitation of $\mathrm{CaCO}_{3}$ from homogeneous solutions, J. Cryst. Growth 169 (1996) 339-346.

[24] H.K. Yang Xiaoqing, Zhao Yanyan, Special effect of calcium sulfate crystallization under microwave irradiation, J. Inorg. Mater. 21 (2006) 6.

[25] Y. Liu, Y.J. Cui, H.Y. Mao, R. Guo, Calcium carbonate crystallization in the presence of casein, Cryst. Growth Des. 12 (2012) 4720-4726.

[26] D. Chakraborty, V.K. Agarwal, S.K. Bhatia, J. Bellare, Steady-state transitions and polymorph transformation in continuous precipiation of calciumcarbonate, Ind. Eng. Chem. Res. 33 (1994) 2187-2197.

[27] D. Zhou, E.V. Anoishkina, V.H. Desai, K.J. Casey, Synthesis and characterization of calcium carbonate whiskers, Electrochem. Solid-State Lett. 1 (1998) $133-135$. 